\title{
The basidiomycetous yeast Trichosporon may cause severe lung exacerbation in cystic fibrosis patients - clinical analysis of Trichosporon positive patients in a Munich cohort
}

Carolin Kröner ${ }^{1}$, Matthias Kappler ${ }^{1}$, Ann-Christin Grimmelt', Gudrun Laniado ${ }^{1}$, Benjamin Würstl ${ }^{2}$ and Matthias Griese ${ }^{1 *}$

\begin{abstract}
Background: The relevance of Trichosporon species for cystic fibrosis (CF) patients has not yet been extensively investigated.

Methods: The clinical course of CF patients with Trichosporon spp. in their respiratory secretions was analysed between 2003 and 2010 in the Munich CF center. All respiratory samples of 360 CF patients ( 0 - 52.4 years; mean FEV1 2010 81.4\% pred) were investigated.

Results: In 8 patients (2.2\%, 3 male, mean age 21.8 years) Trichosporon was detected at least once. One patient carried T. asahii. One patient carried T. mycotoxinivorans and one patient T. inkin as determined by DNA sequencing. As potential risk factors for Trichosporon colonization steroid treatment, allergic bronchopulmonary aspergillosis (ABPA) and CF associated diabetes were identified in 6, 5, and 2 patients respectively. For one patient, the observation period was not long enough to determine the clinical course. One patient had only a single positive specimen and exhibited a stable clinical course determined by change in forced expiratory volume in one second (FEV1), body-mass-index (BMI), C-reactive protein (CRP) and immunoglobulin $\mathrm{G}(\mathrm{lgG})$. Of 6 patients with repeatedly positive specimen (mean detection period 4.5 years), 4 patients had a greater decline in FEV1 than expected, 2 of these a decline in BMI and 1 an increase in IgG above the reference range. 2 patients received antimycotic treatment: one patient with a tormenting dry cough subjectively improved under Amphotericin B inhalation; one patient with a severe exacerbation due to T. inkin was treated with i.v. Amphotericin B, oral Voriconazole and Posaconazole which stabilized the clinical condition.

Conclusions: This study demonstrates the potential association of Trichosporon spp. with severe exacerbations in CF patients.
\end{abstract}

Keywords: Cystic fibrosis, Trichosporon species, Respiratory pathogens, Exacerbations

\section{Background}

Trichosporon species (T. spp.) belong to the genus of basidiomycetous yeast and are widely distributed in nature. They are found in soil and water and are known to colonize skin and gastrointestinal tract of humans [1,2]. Numerous Trichosporon spp. have been characterized [3], while only a few cause human

\footnotetext{
* Correspondence: matthias.griese@med.uni-muenchen.de

'Pediatric Pneumology and Christiane Herzog Cystic Fibrosis Center, Dr. von Hauner Children's Hospital, Ludwig-Maximilians University, Lindwurmstr. 4 , 80337 Munich, Germany

Full list of author information is available at the end of the article
}

disease including T. asahii, T. inkin, T. asteroides, $T$. cutaneum, T. mucoides, T. ovoides (formerly subsumed as a single species: $T$. beigelii $[4,5]$ ) and two more recently described species: T. louberi and japonicum [6]. The most relevant disease entities caused by Trichosporon spp. are white piedra, a mycosis of the hair (T. inkin, T. ovoides) [4], summer-type hypersensitivity pneumonitis in Japan (T. asahii, T. mucoides and T. dermatis) [4] and invasive trichosporonosis (local and disseminated; most often caused by T. asahii) [4]. Risk factors for invasive trichosporonosis are immunosuppression, including prolonged corticosteroid treatment, impaired granulocyte function,

\section{Biomed Central}


neutropenia, malignancies, especially leukemia [7], renal disease, extensive burns and HIV [7,8]. Invasive Trichosporon infections are the second most common yeast fungaemia in humans [4,9], especially in patients with haematological malignancies [10]. Symptoms of invasive trichosporonosis range from pulmonary infiltrates, skin lesions and renal failure to local organ infections, such as hepatitis [4].

The significance of Trichosporon spp. for CF patients has so far not been widely recognized. Only three case reports are available in literature: One 11-year old CF patient suffered from a non-aspergillus allergic bronchopulmonary mycosis due to $T$. beigelii and recovered within 2 months under intensive steroid and antifungal therapy [11]. One 20-year old, male CF patient died within a few days from admission due to a fulminant pneumonia with T. mycotoxinivorans [12] and one 35year old CF patient died due to a disseminated fatal infection with T. mycotoxinivorans 29 days after lung transplantation [13]. Aim of this study was to investigate the detection rate of Trichosporon spp. in a German CF cohort and to describe the clinical course of patients positive for Trichosporon.

\section{Methods}

All respiratory samples of $360 \mathrm{CF}$ patients (mean age 201018.11 years, range 0 - 52.4; mean FEV1 81.4\% pred; range 16 - $136 \%$ pred; $12.5 \%$ with associated diabetes mellitus) who attended the CF Center at the Children's University Hospital in Munich were studied between January 1st, 2003 and December 31st, 2010 for the presence of bacterial and/or fungal pathogens. Other detected fungi included Aspergillus species (approximately $16 \%$ of the cohort, $>90 \%$ Aspergillus fumigatus) and Candida species (approximately $40 \%$ of the cohort, $>90 \%$ Candida albicans). 15\% of the patients exhibited intermittent Pseudomonas aeruginosa colonization, 48\% chronic colonization. Patient visits took place on average every three months, if indicated more often. At each visit, sputum samples or throat smears were taken and the patients were investigated clinically; routine laboratory examinations including inflammatory parameters and lung-function tests were performed. On average 4 respiratory samples/patient/year were analysed, approximately $70 \%$ of the samples were throat swabs, $30 \%$ expectorated sputum. The clinical course of Trichosporon positive patients was analysed retrospectively based on forced expiratory volume in one second (FEV1,\%pred), body mass index (BMI) and the inflammatory markers CRP (mg/l) and immunoglobulin G (IgG, g/l), the latter known to be associated with chronic inflammation and inversely correlated with lung function and long-term prognosis $[14,15]$. The erythrocyte sedimentation rate $1 \mathrm{~h}$ (ESR, $\mathrm{mm}$ ) was also recorded; however, insufficient data was available for analysis. Decline in FEV1 was defined as a drop of the yearly mean FEV1 of $>1 \%$ pred/year from first detection to the end of the observation period of the individual patient, based on the average yearly drop of FEV1 values of $1 \%$ in large CF registries [16]. Any change in BMI was recorded, increase in CRP was defined as an increase by $>5 \mathrm{mg} / \mathrm{l}$ and an increase in IgG was defined as an increase by $>3 \mathrm{~g} / \mathrm{l}$ from first detection to the end of the observation period. Informed consent was obtained from all participants and the study was approved by the institutional review board of the University of Munich.

\section{Specimen characterization}

Microbiological examinations were routinely performed at the department of microbiology at the Dr. von Hauner Children's hospital in Munich. Specimen with newly identified microorganisms were also analysed at the Max von Pettenkofer-Institute in Munich (National Consiliary Laboratory for CF Bacteriology, South Germany). Clinical specimens were diluted 1:2 with Dithiothreitol (DTT; Sigma, Deisenhofen, Germany) solution (1 mg/ml) for liquefaction. For quantitative bacteriology sputum samples were diluted $10^{-1}, 10^{-4}$ and $10^{-5}$ with $0,9 \% \mathrm{NaCl}$ and plated on Trypticase soy agar (TSA) and McConkey Agar. DTT-pretreated samples were further streaked on Columbia Agar with 5\% sheep blood, Chocolate agar, Sabouraud-Glucose-Agar for fungi as well as on selective media containing either $8 \mu \mathrm{g} / \mathrm{ml}$ Meropenem or $16 \mu \mathrm{g} / \mathrm{ml}$ Polymyxin B to recover Carbapenem-resistent gramnegative bacteria and Burkholderia cepacia complex isolates, respectively. Columbia Agar and Chocolate agar were incubated at $32^{\circ} \mathrm{C}$ under anaerobic conditions to prevent overgrowth of clinically important bacteria such as $H$. influenza by $P$. aeruginosa, while all other media were incubated aerobically at $32^{\circ} \mathrm{C}$. All bacteriological cultures were incubated for 3-5 days and Sabouraud-Glucose-Agar for at least 10 days. Species identification was performed by routine microbiological procedures. Yeasts were isolated on chromogenic Agar plates for differentiation. Filamentous fungi were primarily differentiated by micromorphological examinations.

Trichosporon spp. in pts 1,2,4,6,7,8 were identified by alternative biochemical test (API $20 \mathrm{C}$ AUX and ID 32 C galleries bioMérieux, Mercy l'Etoile, France). T. asahii (patient 2) was identified by microscopic identification, biochemical testing and Matrix Assisted Laser Desorption Ionisation - Time of flight Mass Spectrometry (MALDITOF MS Biotyper system Bruker Daltonics). Three strains (two strains of patient 3 , one strain of patient 5) were further analysed - prompted by the clinical deterioration of these patients after Trichosporon detection. In a first step these strains were identified by the MALDI-TOF MS BioTyper system; in a second step DNA sequencing was 
performed to confirm the MALDI-TOF results. MALDITOF MS is a reliable method to rapidly identify fungal species, and can be used as an alternative to PCR-based techniques $[17,18]$, which have been extensively used for the identification of Trichosporon spp. [19]. DNA sequencing of conserved (D1/D2 region of the $28 \mathrm{~S} \mathrm{rDNA}$ ) and variable regions (ITS and IGS1 regions) are common methods to determine Trichosporon spp. [20,21].

In this study the detected mass spectra in the MALDITOF analysis of the two patients 3 and 5 (scores $>1.700$ ) were compared to the reference spectra of Trichosporon spp. included in the MALDO Biotyper BDAL MSP library. The results were confirmed by DNA sequencing: Parts of the $28 \mathrm{~S}$ rDNA were sequenced and compared with fungal consensus sequences of Trichosporon spp. in the NCBI BLAST ${ }^{\circledR}$. Parts of the $28 \mathrm{~S}$ rDNA region were amplified by PCR using the following oligonucleotide primers: primer P1( 45-64): 5'-ATCAATAAGCGGAG GAAAAG-3' and primer P2 (825-843): 5'-CTCTGG CTTCACCCTATTC-3'. The identity of sequenced strains was $99.0 \%$ for $T$. inkin and T. mycotoxinivorans respectively. Figure 1 demonstrates the discrimination between the sequenced isolates and the most common Trichosporon spp. Due to varying lengths of published sequences (500 to $1000 \mathrm{bp}$ ) a comparable sequence length of 562 bp was used to realize the alignment performed by MegAlign, software version 8.1.4, Lasergene, DNASTAR $^{\circledR}$.

\section{Results}

Trichosporon spp. were detected in 8 of 360 patients (i.e. 2.2\%; 3 male; mean age: 21.8 years, range: $8-41.1$; Table 1 ). Two Trichosporon spp. were specified by MALDI-TOF MS and by DNA sequencing: T. mycotoxinivorans and $T$. inkin. T. asahii was identified by microscopy, biochemical testing and MALDI-TOF MS. All but one patient were colonized with further CF typical microorganisms at first detection as depicted in Table 1.5 patients had a history of ABPA 0-5 years prior to first detection. 5 patients had a history of treatment with nebulized steroids and/ or steroid inhalers, 3 of whom had received additional systemic steroid treatment, one patient had received systemic steroid treatment only. 2 patients had CF associated diabetes at first detection. No patient underwent lung transplantation. All 8 patients had a dF508 mutation, 3 patients an additional stop mutation (2 patients R553X and one patient S466X) (Table 1).

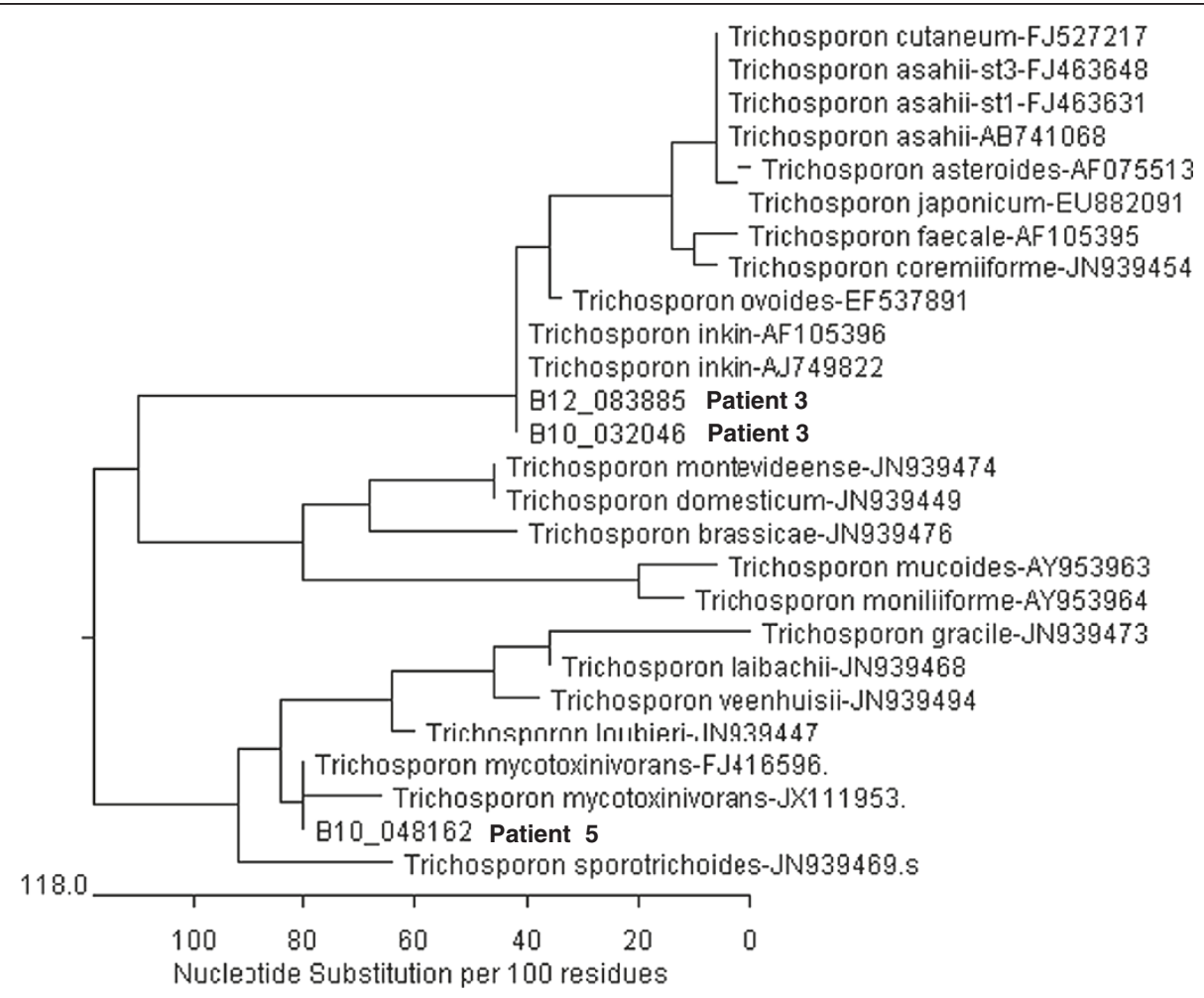

Figure 1 Phylogenetic tree of Trichosporon spp (28S rDNA). Discrimination between the sequenced isolates of patient 3 (one isolate from 2010 and one from 2012) and of patient 5 and the most common Trichosporon spp (NCBI Blast). A comparable sequence length of 562 bp was used to realize alignment, performed by MegAlign, software version 8.1.4, Lasergene, DNASTAR. The bar shown in the graph provides scale to the branch lengths and represents the number of substitutions per 100 residues. 
Table 1 Characterization and follow-up of CF patients positive for Trichosporon

\begin{tabular}{|c|c|c|c|c|c|c|c|c|}
\hline Patient number & 1 & 2 & 3 & 4 & 5 & 6 & 7 & 8 \\
\hline Sex & $\mathrm{F}$ & $M$ & $\mathrm{~F}$ & M & $\mathrm{F}$ & $\mathrm{F}$ & M & $\mathrm{F}$ \\
\hline Mutation & dF508/ dF508 & dF508/ dF508 & dF508/ Nk & dF508/ R553X & dF508/ S466X & dF508/ Nk & dF508/ Nk & dF508/ R553X \\
\hline Age at first detection (y) & 41.1 & 33.0 & 10.0 & 11.0 & 21.7 & 8.0 & 22.3 & 27.6 \\
\hline Age at last detection (y) & 43.0 & 36.9 & 17.8 & 11.0 & 28.4 & 8.6 & 29.2 & 28.4 \\
\hline Follow up $(y)^{*}$ & 3.1 & 5.9 & 7.8 & 2.4 & 6.7 & 5.3 & 6.9 & 0.8 \\
\hline Trichosporon species & Nk & Asahii & Inkin & Nk & Mycotoxinivorans & Nk & Nk & Nk \\
\hline $\begin{array}{l}\text { Other isolated } \\
\text { organisms from sputum } \\
\text { (at first detection) }\end{array}$ & $\begin{array}{l}\text { Ps ae (chron), } \\
\text { Ps ae muc }\end{array}$ & $\begin{array}{l}\text { E col, Prot } \\
\text { mirab }\end{array}$ & None & $\begin{array}{l}\text { Norcard farc, Inqu lin, } \\
\text { Burc cep, Asp fum, } \\
\text { Penicill sp }\end{array}$ & $\begin{array}{l}\text { Ps ae (chron), } \\
\text { Cand alb }\end{array}$ & $\begin{array}{l}\text { Acinet baum, } \\
\text { fungi (not spec), } \\
\text { Ps ae (chron) }\end{array}$ & $\begin{array}{l}\text { Ps ae (chron), } \\
\text { Ps ae muc, Cand alb }\end{array}$ & $\begin{array}{l}\text { Ps ae muc } \\
\text { (chron), Cand alb }\end{array}$ \\
\hline $\begin{array}{l}\text { Other isolated } \\
\text { organisms from } \\
\text { sputum (throughout } \\
\text { observation period) }\end{array}$ & $\begin{array}{l}\text { Pseudoall boyd (rep), Cand } \\
\text { glab (rep), Cand alb (rep), } \\
\text { Cand paraps (rep), Enteroc } \\
\text { spp. (rep), Asp fum (rep) }\end{array}$ & $\begin{array}{l}\text { Prot mirab } \\
\text { (rep), Asp } \\
\text { fum (rep) }\end{array}$ & $\begin{array}{l}\text { Asp fum (rep), Sten } \\
\text { mal (rep), Cand alb } \\
\text { (rep), Sa (rep) }\end{array}$ & $\begin{array}{l}\text { Inqu lin (rep), Burc } \\
\text { cep (rep), Penicill sp } \\
\text { (rep), Acinet fum (rep), } \\
\text { Ps put (once) }\end{array}$ & $\begin{array}{l}\text { E coli (rep), Sten } \\
\text { malt (rep), Asp } \\
\text { flav (rep) }\end{array}$ & $\begin{array}{l}\text { Acinet baum } \\
\text { (rep), Pet sord (rep) }\end{array}$ & $\begin{array}{l}\text { Asp fum (rep), Prot } \\
\text { mirab (rep), Sa (rep), } \\
\text { Enteroc spp (rep), } \\
\text { Cand alb (rep) }\end{array}$ & Cand paraps (rep) \\
\hline
\end{tabular}

Antibiotic regimen

prior to first detection

(agent; regimen)

\begin{tabular}{|c|c|c|c|c|c|c|c|c|}
\hline Oral & Cip (cont) & $\begin{array}{l}\text { Cefur (cont), } \\
\text { Cip ( } 2 \text { w on/off) }\end{array}$ & $\begin{array}{l}\text { Cep (cont), } \\
\text { Cip ( } 2 \text { w on/off) }\end{array}$ & $\begin{array}{l}\text { Ceph (cont), } \\
\text { Cip ( } 2 \text { w on/off) }\end{array}$ & Ceph (cont) & $\begin{array}{l}\text { Ceph (cont), cip (2 } \\
\text { w on/off) }\end{array}$ & Ceph (cont) & Cot (cont) \\
\hline Inhaled & Tob/col (2 w on/off) & None & Col (2 w on/off) & Tob/col (2 w on/off) & Gern (2 w on/off) & None & Gern (2 w on/off) & $\begin{array}{l}\text { Gern/col } \\
\text { (2 w on/off) }\end{array}$ \\
\hline iv (courses/y) & 2 & 2 & 1 & 1 & 2 & 1 & 1 & 2 \\
\hline $\begin{array}{l}\text { Diabetes mellitus } \\
\text { (at first detection) }\end{array}$ & Yes & Yes & no & No & No & No & No & No \\
\hline $\begin{array}{l}\text { ABPA (years prior } \\
\text { to first detection) }\end{array}$ & $5 y, 2 y$ & 3y & no & $3 y, 1 y$ & No & $\begin{array}{l}1 \text { y after first } \\
\text { detection }\end{array}$ & No & At first detection \\
\hline $\begin{array}{l}\text { Nebulized/inhaled } \\
\text { steroids prior to first } \\
\text { detection (duration) }\end{array}$ & Yes (5y, rep) & No & No & Yes (2.5y) & Yes (2y) & Yes (1y) & No & $\begin{array}{l}\text { Yes (from } \\
\text { first detection on) }\end{array}$ \\
\hline $\begin{array}{l}\text { Intermittent systemic } \\
\text { steroids prior to } \\
\text { first detection }\end{array}$ & Yes & Yes & No & Yes & Yes & No & No & $\begin{array}{l}\text { Yes (from first } \\
\text { detection on) }\end{array}$ \\
\hline $\begin{array}{l}\text { Lung function } \\
\text { FEV } 1 \text { (\% pred) })^{* *}\end{array}$ & Decline & Stable & Decline & Increase & Decline & Increase & Decline & $\mathrm{Np}$ \\
\hline At first detection & 61.2 & 49.3 & 81.2 & 84.3 & 86.3 & 68.2 & 40.1 & 61.3 \\
\hline At end of observation & 43.1 & 47.2 & 57.3 & 88.3 & 79.0 & 79.6 & 30.0 & $\mathrm{~Np}$ \\
\hline BMI $\left(\mathrm{kg} / \mathrm{m}^{2}\right)^{* * *}$ & Decline & Stable & Increase & Increase & Increase & Increase & Decline & $\mathrm{Np}$ \\
\hline At first detection & 18.9 & 25.8 & 13.7 & 15.5 & 19.6 & 15.1 & 19.3 & 21.5 \\
\hline At end of observation & 18.2 & 25.8 & 17.8 & 16.3 & 19.9 & 18 & 18.5 & $\mathrm{~Np}$ \\
\hline $\lg G(g / l)^{* * * *}$ & Increase $^{+}$ & Stable & increase & Stable & Stable & Stable & Increase & $\mathrm{Np}$ \\
\hline
\end{tabular}


Table 1 Characterization and follow-up of CF patients positive for Trichosporon (Continued)

\begin{tabular}{|c|c|c|c|c|c|c|c|c|}
\hline At first detection & 18.8 & 13.0 & 8.1 & 8.2 & 10.4 & 9.5 & 13.4 & 9.2 \\
\hline At end of observation & 22.4 & 13.7 & 13.1 & 10.2 & 11.7 & 9.6 & 17.1 & $\mathrm{~Np}$ \\
\hline CRP $(\mathrm{mg} / \mathrm{l})^{* * * * * *}$ & Increase & $\mathrm{Na}$ & Increase & Stable & Stable & Stable & Decrease & $\mathrm{Np}$ \\
\hline At first detection & 6.2 & 11.1 & $<1.0$ & $<1.0$ & 3.5 & $<1.0$ & 19.9 & 17.9 \\
\hline At end of observation & 30.7 & $\mathrm{Na}$ & 11.7 & $<1.0$ & 5.4 & 4.1 & 6.7 & $\mathrm{~Np}$ \\
\hline
\end{tabular}

At end of observation 30.7

*years from first detection to Trichosporon to end of observation period, **change throughout the observation period of the individual patient, decline defined as $\Delta \mathrm{FEV} 1>1 \%$ pred/year, ${ }^{* * *}$ change in BMI throughout the observation period, ${ }^{* * * *}$ change throughout the observation period, change defined as $\Delta \mathrm{lgG}>3 \mathrm{~g} / \mathrm{l},{ }^{* * * * *}$ change throughout the observation period, change defined as $\Delta C \mathrm{CRP}>5 \mathrm{mg} / \mathrm{l},+$ above reference range. Abbreviations: $N a=$ not available, $N k=$ not known, $n p=$ not possible, chron = chronic, cont = continuous, rep $=$ repeated, $/=$ alternating, $w=$ weeks, $y=$ years, Acinet baum $=$ Acinetobacter baumannii, Acinet

fum = Acinetobacter fumigatus, Asp flav = Aspergillis flavipes, Asp fum = Aspergillus fumigatus, Burc cep= Burkholderia cepacia, Cand alb=Candida albicans, Cand glab = Candida glabrata, Cand paraps = Candida

parapsilosis, Cefu = cefuroxim, Cep = ceporexin, Ceph = cephalexin, Cip = ciprofloxacin, Col = colistin, Cot = cotrimoxazole, E coli = Escherichia coli, Gern = gernebcin, Inqu lin = Inquilinus limosus, Nocard farc = Norcarderia facrinica, Pet sord = Petriella sordida, Penicill $S p=$ Penicillium sp, Prot mirab = Proteus mirabilis, Pseudoall boyd $=$ Pseudoallescheria boydii, Ps ae $=$ Pseudomonas aeruginosa, $P s$ ae muc $=$ Pseudomonas aeruginosa mucoides, Ps put $=$ Pseudomonas putida, $S a=$ Staphylococcus aureus, Sten malt $=$ Stenotrophomonas maltophilia, $T o b=$ tobramycin. 


\section{Clinical course of patients positive for Trichosporon}

The observation period for patient 8 was 0.8 years and thus not long enough for an analysis of the clinical course. One patient (4) had only a single positive respiratory specimen and exhibited a stable FEV1, stable CRP, IgG and an increase in BMI. The other 6 patients $(1,2,3,5,6,7)$ had repeatedly Trichosporon positive specimens with a mean detection period of 4.5 years (range 0.6 - 7.1). FEV1, BMI, CRP and IgG remained stable in 1 , respectively 2 of these patients $(2,6)$ with a mean detection period of 2.5 years (range $0.6-3.9$ ). FEV1 declined by a mean $\triangle F E V 1$ of -2.9 pred\%/year (range -1.1 pred\%/year to -5.8 pred\%/year) in 4 patients $(1,3,5,7)$ with repeated positive samples and a mean detection period of 5.7 years (range 1.9-7.1). CRP increased in 2 of these patients $(1,3)$ and IgG increased for 3 of these patients $(1,3,7)$, in patient 1 above the reference range. BMI declined in $2(1,7)$ of these patients (Table 1, Figure 2).

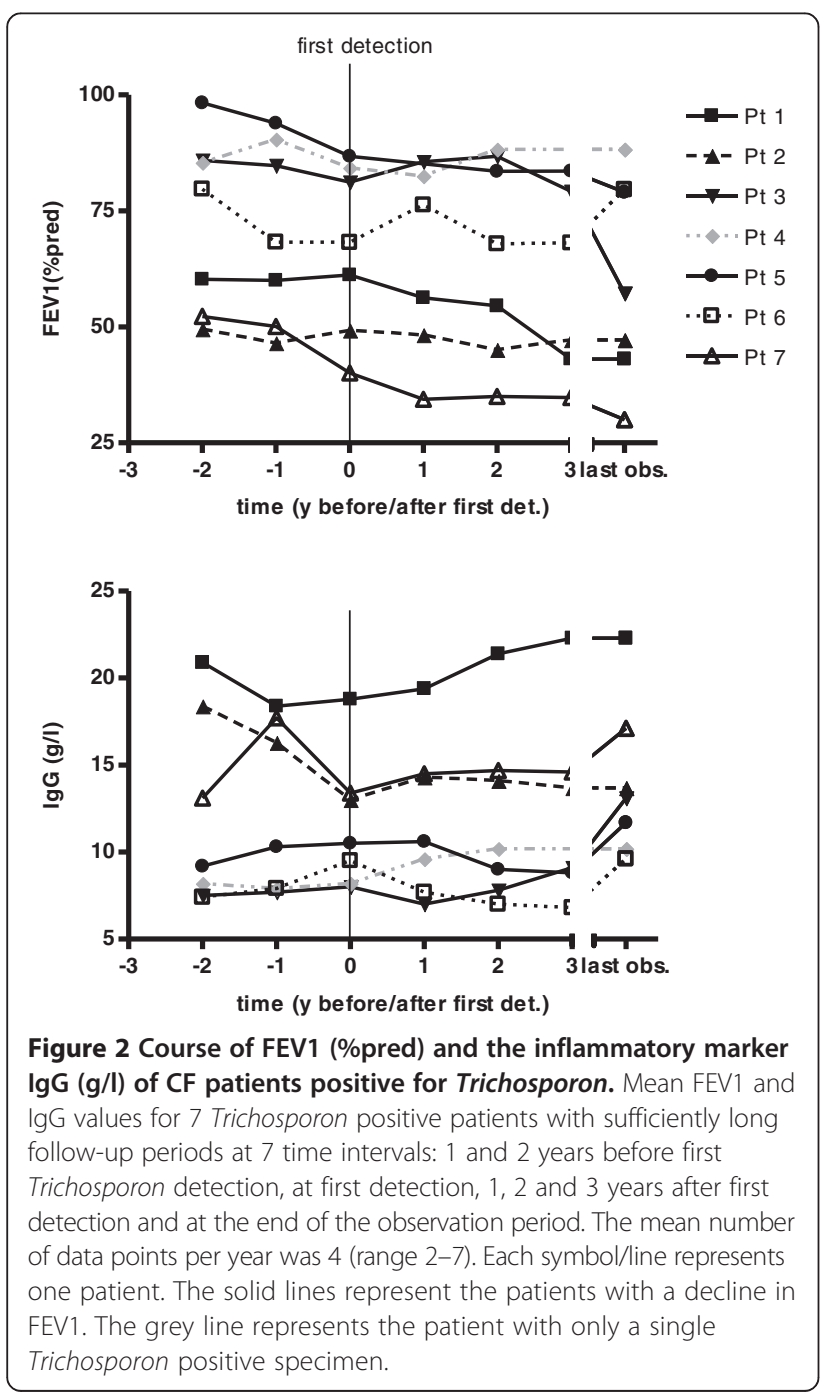

\section{Treatment}

Patients 3 and 5 received antimycotic treatment due to an unexplained but marked deterioration of the clinical status. Patient 5 with a prolonged detection period of T. mycotoxinivorans exhibited a recurrent and tormenting dry cough; she reported a substantial subjective improvement of the dry cough after inhalation with nebulized Amphotericin B (not liposomal, $15 \mathrm{mg}$ 1:1 diluted with distilled water, $1 \mathrm{x} /$ day for 4-8 weeks, 3x/year). T. mycotoxinvorans however persisted in the sputum. Patient 3 is described in detail below.

\section{Clinical course of patient 3}

Until the age of 16 years a female CF patient ( $\Delta$ F508/ not known) with pancreatic insufficiency had only minor respiratory symptoms, FEV1 values between 85 and 106 pred\% and a BMI between the 3rd to 5 th percentile. Trichosporon spp. was detected for the first time at the age of 10 years (Figure 3a). Further respiratory pathogens at first detection of Trichosporon included Stenotrophomonas maltophilia, Staphylococcus aureus, Candida albicans and Aspergillus fumigatus (Figure 3b). The patient was treated with standard CF therapy and had no history of systemic or nebulized steroids. At the age of 16 years, the stable clinical course was disrupted by 4 severe exacerbations within 12 months requiring intensive treatment (Figure 3a). The patient exhibited dyspnea, bloody sputum, an oxygen saturation of $89 \%$ in ambient air, night sweats, and a weight loss of $5 \mathrm{~kg}$. FEV1 dropped to 45 pred\% (Figure 4). Due to the lack of response to intensive i.v. antibiotic and supportive treatment in the presence of Trichosporon inkin, i.v. antimycotic treatment with liposomal Amphotericin B (4.6 mg/kg/d) was initiated; nebulized Amphotericin B was not tolerated. Resistance testing of Trichosporon inkin revealed good effectiveness of Amphotericin B, Posaconazole and Voriconazole. After 8 weeks of Amphotericin treatment, the patient's condition improved considerably and oral therapy with Voriconazole was initiated. FEV1 had increased from 45 pred\% to 65 pred\% (Figure 4). The patient developed an impaired color vision and Voriconazole was replaced with Posaconazole, which has been continued since. 12 months later 3 more episodes of clinical deterioration had been treated with i.v antibiotics and i.v. Amphotericin B. The clinical status stabilized with FEV1 values between 55 and 70 pred\%. The chest $\mathrm{x}$-rays taken 2 months and 2 years after the first exacerbation show the extent of damage (Figure 5). Trichosporon inkin persists in the sputum until the current age of 17.8 years.

\section{Discussion}

The relevance of fungal colonization in CF patients has only recently been recognized [22]. Colonization with $C$. albicans and $A$. fumigatus -also in non-ABPA patients- 


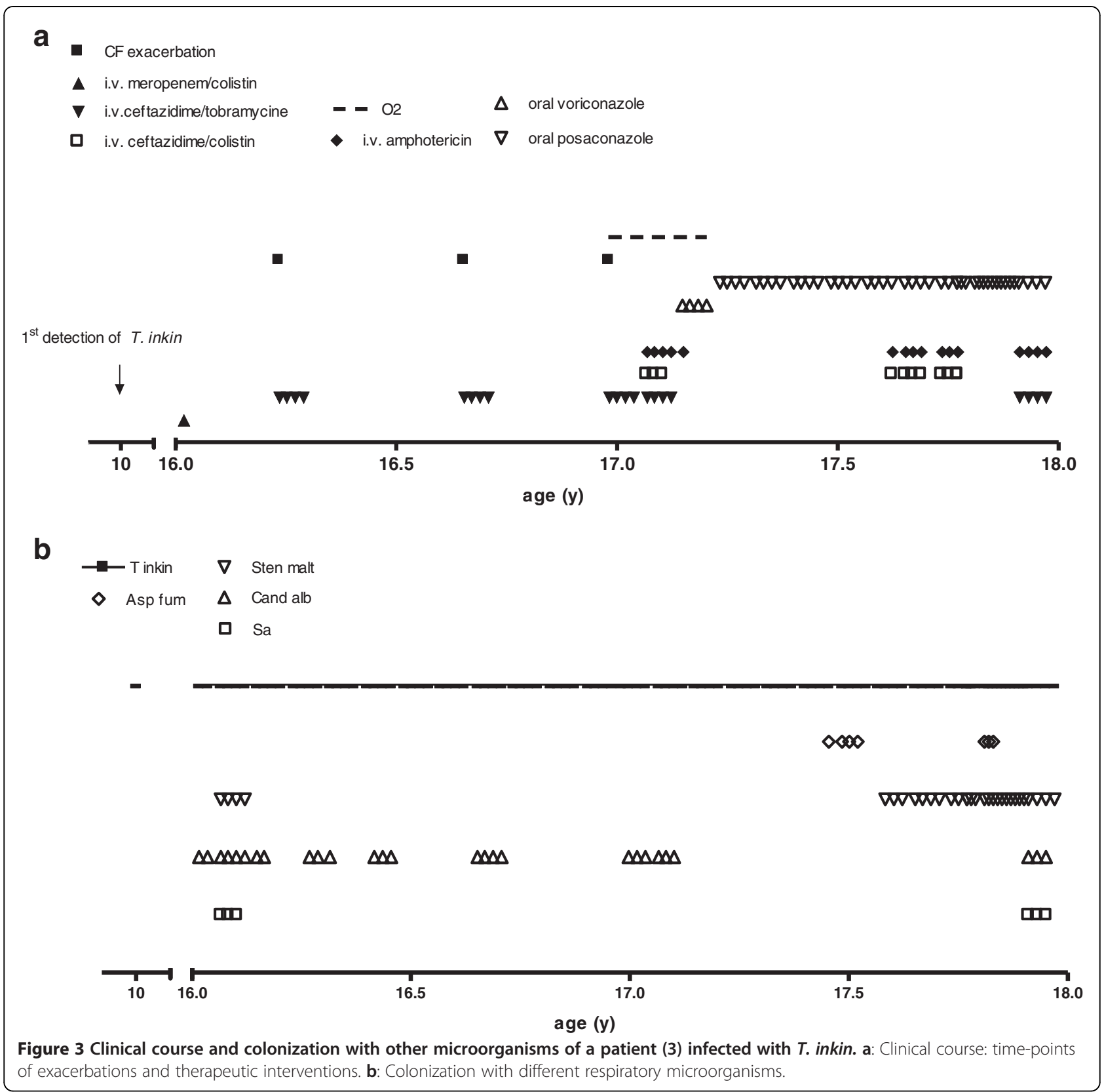

has for example been associated with a decline in lung function and a negative effect on the clinical outcome $[23,24]$. A fumigatus in particular was demonstrated to have a pro-inflammatory effect on the CF epithelium [25]. However, the available studies are limited by important confounders, such as the lack of standardized detection methods or co-infection with other microorganisms. The contribution of fungi to CF lung disease thus remains controversial as does the indication to a non-risk free antifungal therapy.

The prevalence and the relevance of Trichosporon spp. in CF has to date not been investigated. In the present study Trichosporon spp. was found in respiratory samples of $2.2 \%$ of the cohort over an eight year period. Colonization rates of Trichosporon spp. in non-CF patients range between $0.8 \%$ in throat cultures and $3.1 \%$ in stool cultures of patients in a large Veterans hospital [26] and 3.7\% in stool, skin or urine of 317 immunosuppressed hosts [27].

Risk factors for colonization and/or infection with Trichosporon in CF are also unknown. Invasive trichosporonosis in non-CF patients has been associated with mucosal disruption and general immune dysfunction due to HIV or malignancies [28], however, the exact pathophysiology of Trichosporon infections is unknown. It is possible that mucosal disruption in CF also predisposes 

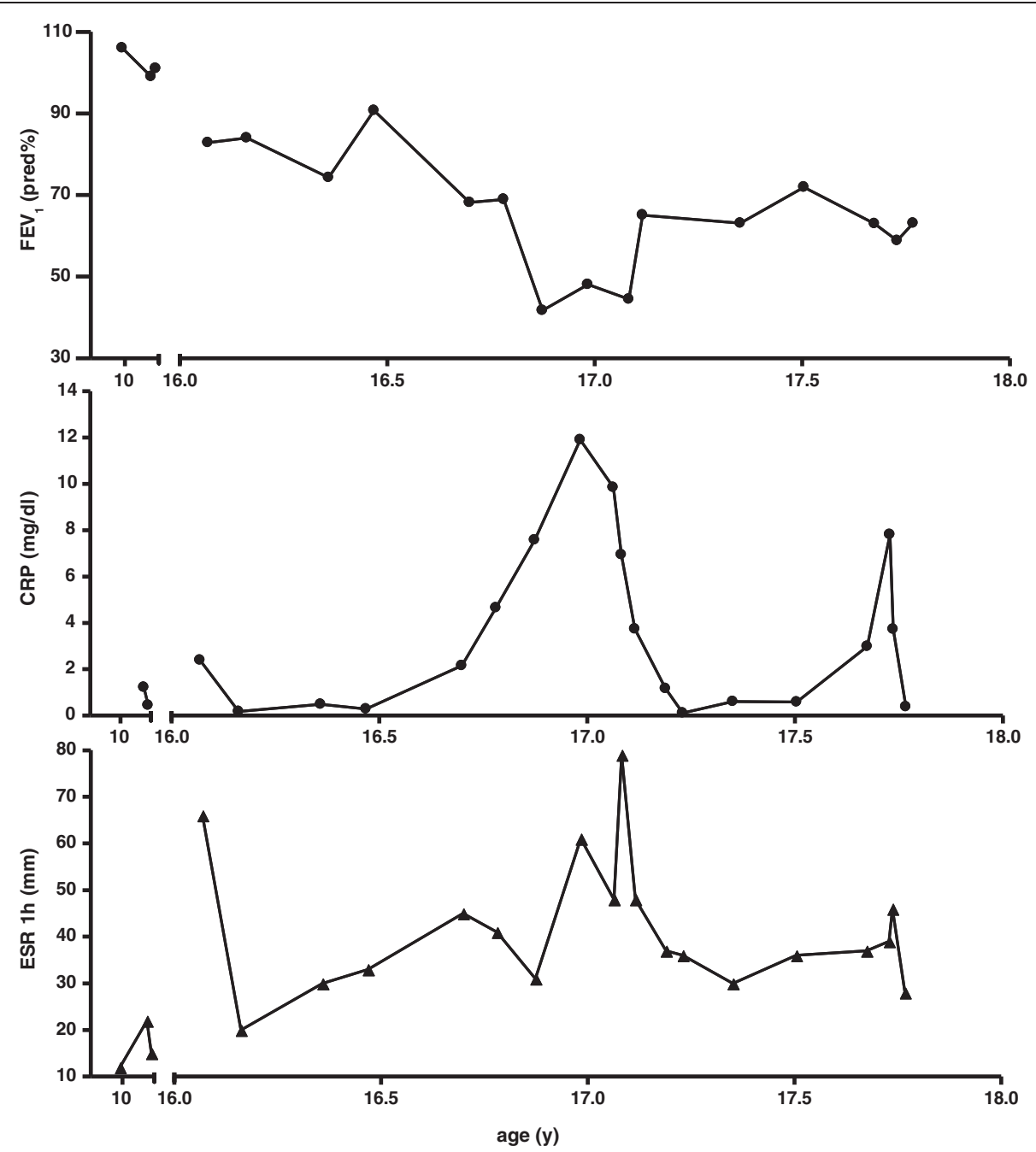

Figure 4 Course of FEV1 (\% pred), CRP ( $\mathrm{mg} / \mathrm{dl})$ and ESR $1 \mathrm{~h}(\mathrm{~mm})$ of a patient (3) infected with $T$. inkin.
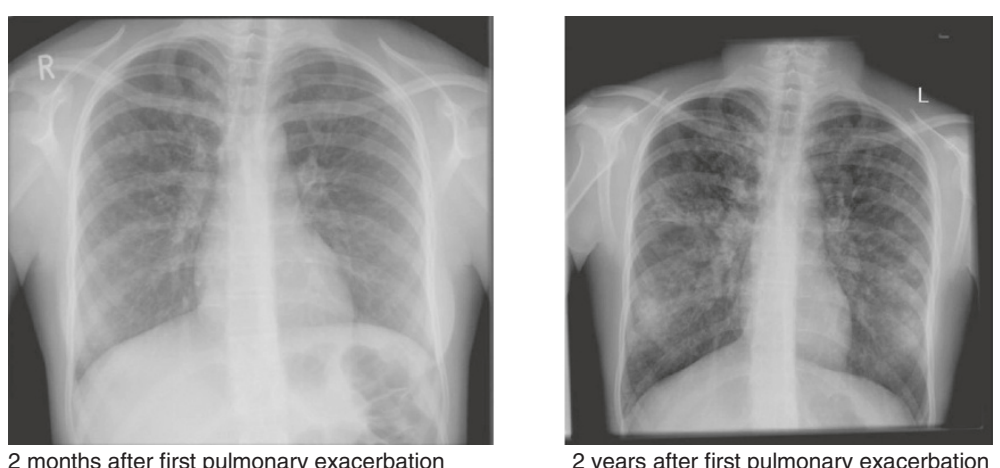

Figure 5 Chest X-ray of a patient (3) infected with $T$. inkin two months and two years after first pulmonary exacerbation due to T. inkin. The second X-ray demonstrates a strong increase in hyperinflation, increasing bronchiectasis and mucus plugging, increasingly thickened bronchial walls and numerous additional patchy lesions. 
for Trichosporon colonization. Our data suggest that age, prior systemic or inhaled steroid treatment, ABPA and possibly CF associated diabetes might predispose for Trichosporon colonization. 3 of 8 patients carried a stop mutation in addition to dF508, which is higher than the general frequency of stop mutations in German CF population (1.8\% for R553X; <1\% for S466X) [29]. Our data further indicate that longer Trichosporon detection periods may be associated with a decline in lung function and BMI, and increased inflammation. Chronic airway colonization with Trichosporon may harbour the risk of clinically relevant infection leading to unstable lung disease. Further studies will have to corroborate these findings.

Limitations of the current study include the relatively small amount of patients, the retrospective design, the presence of other microorganisms as a confounder and the lack of specification of all Trichosporon spp. Standardized diagnostic procedures were subsequently introduced.

Up to now three case reports of CF patients have demonstrated the potential of exacerbation and in two cases of a fatal, disseminated infection due to Trichosporon spp. [11-13]. Here we add another patient (3) whose course was significantly affected by infection with $T$. inkin. This conclusion is based on the unexplained failure of intensive antibacterial and supportive therapy and the clear improvement and stabilization of the clinical status after the initiation of antifugal therapy. Repeated detection of Trichosporon spp. may indicate CF patients at risk for deterioration; preemptive treatment may be considered.

\section{Conclusion}

To conclude, emerging pathogens relevant for CF lung disease may include the basidiomycetous yeast Trichosporon. Its detection in respiratory secretions in patients not responding to standard antimicrobial therapy may warrant targeted antifungal therapy.

\section{Competing interests}

The authors declare that they have no competing interests.

\section{Authors' contributions}

MG, and CK designed the study. MG and CK collected the data and drafted the manuscript. MK and AC participated in the design and coordination of the study and helped to draft the manuscript. BM and GL performed the microbiological studies. All authors read and approved the final manuscript.

\section{Acknowledgements}

We thank Ms Traudl Wesselak for her support in the acquisition of data. The authors were not funded for this study.

\section{Author details}

'Pediatric Pneumology and Christiane Herzog Cystic Fibrosis Center, Dr. von Hauner Children's Hospital, Ludwig-Maximilians University, Lindwurmstr. 4, 80337 Munich, Germany. ${ }^{2}$ Max von Pettenkofer Institute, Ludwig-Maximilians University, Pettenkoferstr. 9a, 80336 Munich, Germany.

Received: 8 February 2013 Accepted: 28 October 2013

Published: 1 November 2013

\section{References}

1. Pritchard RC, Muir DB: Trichosporon Beigelii - survey of isolates from clinical material. Pathology 1985, 17(1):20-23.

2. Walsh TJ, Melcher GP, Lee JW, Pizzo PA: Infections due to Trichosporon species: new concepts in mycology, pathogenesis, diagnosis and treatment. Curr Top Med Mycol 1993, 5:79-113.

3. Molnar O, Schatzmayr G, Fuchs E, Prillinger $\mathrm{H}$ : Trichosporon mycotoxinivorans sp. nov., a new yeast species useful in biological detoxification of various mycotoxins. Syst Appl Microbio/ 2004, 27(6):661-671.

4. Miceli MH, Diaz JA, Lee SA: Emerging opportunistic yeast infections. Lancet Infect Dis 2011, 11(2):142-151.

5. Fleming RV, Walsh TJ, Anaissie EJ: Emerging and less common fungal pathogens. Infect Dis Clin North Am 2002, 16(4):915-933. vi-vii.

6. Agirbasli H, Bilgen H, Ozcan SK, Otlu B, Sinik G, Cerikcioglu N, Durmaz R, Can E, Yalman N, Gedikoglu G, et al: Two possible cases of Trichosporon infections in bone-marrow-transplanted children: the first case of T. japonicum isolated from clinical specimens. Jpn J Infect Dis 2008, 61(2):130-132.

7. Girmenia C, Pagano L, Martino B, D'Antonio D, Fanci R, Specchia G, Mei L, Buelli M, Pizzarelli G, Venditti M, et al: Invasive infections caused by Trichosporon species and Geotrichum capitatum in patients with hematological malignancies: a retrospective multicenter study from Italy and review of the literature. J Clin Microbiol 2005, 43(4):1818-1828.

8. Ruan SY, Chien JY, Hsueh PR: Invasive trichosporonosis caused by Trichosporon asahii and other unusual Trichosporon species at a Medical Center in Taiwan. Clin Infect Dis 2009, 49(1):E11-E17.

9. Chagas TC, Chaves GM, Colombo AL: Update on the genus Trichosporon. Mycopathologia 2008, 166(3):121-132.

10. Tashiro T, Nagai H, Kamberi P, Goto Y, Kikuchi H, Nasu M, Akizuki S: Disseminated Trichosporon-beigelii infection in patients with malignant diseases - immunohistochemical study and review. Eur J Clin Microbiol 1994, 13(3):218-224.

11. Gondor M, Michaels MG, Finder D: Non-aspergillus allergic bronchopulmonary mycosis in a pediatric patient with cystic fibrosis. Pediatrics 1998, 102(6):1480-1482.

12. Hickey PW, Sutton DA, Fothergill AW, Rinaldi MG, Wickes BL, Schmidt HJ, Walsh TJ: Trichosporon mycotoxinivorans, a novel respiratory pathogen in patients with cystic fibrosis. J Clin Microbiol 2009, 47(10):3091-3097.

13. Hirschi S, Letscher-Bru V, Pottecher J, Lannes B, Jeung MY, Degot T, Santelmo N, Sabou AM, Herbrecht R, Kessler R: Disseminated Trichosporon mycotoxinivorans, aspergillus fumigatus, and Scedosporium apiospermum coinfection after lung and liver transplantation in a cystic fibrosis patient. J Clin Microbiol 2012, 50(12):4168-4170.

14. Levy H, Kalish LA, Huntington I, Weller N, Gerard C, Silverman EK, Celedon JC, Pier GB, Weiss ST: Inflammatory markers of lung disease in adult patients with cystic fibrosis. Pediatr Pulmonol 2007, 42(3):256-262.

15. Wheeler WB, Williams M, Matthews WJ Jr, Colten HR: Progression of cystic fibrosis lung disease as a function of serum immunoglobulin $\mathrm{G}$ levels: a 5-year longitudinal study. J Pediatr 1984, 104(5):695-699.

16. De Boeck K, Vermeulen F, Wanyama S, Thomas M: Inhaled corticosteroids and lower lung function decline in young children with cystic fibrosis. Eur Respir J 2011, 37(5):1091-1095.

17. Stevenson LG, Drake SK, Shea YR, Zelazny AM, Murray PR: Evaluation of matrix-assisted laser desorption ionization-time of flight mass spectrometry for identification of clinically important yeast species. J Clin Microbio/ 2010, 48(10):3482-3486.

18. Bader O, Weig M, Taverne-Ghadwal L, Lugert R, Gross U, Kuhns M: Improved clinical laboratory identification of human pathogenic yeasts by matrixassisted laser desorption ionization time-of-flight mass spectrometry. Clin Microbiol Infect 2011, 17(9):1359-1365.

19. Pfaller MA: Epidemiology of fungal infections: the promise of molecular typing. Clin Infect Dis 1995, 20(6):1535-1539.

20. Sugita T, Nishikawa A, Ikeda R, Shinoda T: Identification of medically relevant Trichosporon species based on sequences of internal transcribed spacer regions and construction of a database for Trichosporon identification. J Clin Microbiol 1999, 37(6):1985-1993.

21. Sugita T, Nishikawa A, Shinoda T: Rapid detection of species of the opportunistic yeast Trichosporon by PCR. J Clin Microbiol 1998, 36(5):1458-1460.

22. Liu JC, Modha DE, Gaillard EA: What is the clinical significance of filamentous fungi positive sputum cultures in patients with cystic fibrosis? J Cyst Fibros 2013, 12(3):187-193. 
23. Chotirmall SH, O'Donoghue E, Bennett K, Gunaratnam C, O'Neill SJ, McElvaney NG: Sputum Candida albicans presages FEV(1) decline and hospital-treated exacerbations in cystic fibrosis. Chest 2010, 138(5):1186-1195.

24. Amin R, Dupuis A, Aaron SD, Ratjen F: The effect of chronic infection with aspergillus fumigatus on lung function and hospitalization in patients with cystic fibrosis. Chest 2010, 137(1):171-176.

25. Reihill JA, Moore JE, Elborn JS, Ennis M: Effect of aspergillus fumigatus and Candida albicans on pro-inflammatory response in cystic fibrosis epithelium. J Cyst Fibros 2011, 10(6):401-406.

26. Rose HD, Kurup VP: Colonization of hospitalized patients with yeast-like organisms. Sabouraudia 1977, 15(3):251-256.

27. Haupt HM, Merz WG, Beschorner WE, Vaughan WP, Saral R: Colonization and infection with trichosporon species in the immunosuppressed host. J Infect Dis 1983, 147(2):199-203.

28. Tashiro T, Nagai H, Kamberi P, Goto Y, Kikuchi H, Nasu M, Akizuki S: Disseminated trichosporon beigelii infection in patients with malignant diseases: immunohistochemical study and review. Eur J Clin Microbiol Infect Dis 1994, 13(3):218-224.

29. Tummler B, Storrs T, Dziadek V, Dork T, Meitinger T, Golla A, Bertele-Harms RM, Harms HK, Schroder E, Claass A, et al: Geographic distribution and origin of CFTR mutations in Germany. Hum Gen 1996, 97(6):727-731.

doi:10.1186/1471-2466-13-61

Cite this article as: Kröner et al:: The basidiomycetous yeast Trichosporon may cause severe lung exacerbation in cystic fibrosis patients - clinical analysis of Trichosporon positive patients in a Munich cohort. BMC Pulmonary Medicine 2013 13:61.

\section{Submit your next manuscript to BioMed Central and take full advantage of:}

- Convenient online submission

- Thorough peer review

- No space constraints or color figure charges

- Immediate publication on acceptance

- Inclusion in PubMed, CAS, Scopus and Google Scholar

- Research which is freely available for redistribution 